\title{
Demographics Data Collection Day
}

National Cancer Institute

\section{Source}

National Cancer Institute. Demographics Data Collection Day. NCI Thesaurus. Code C83244.

The day of the week demographics data was collected. 